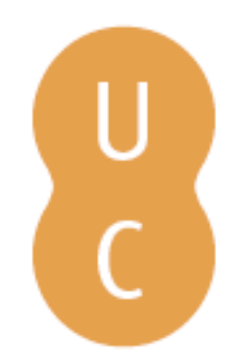

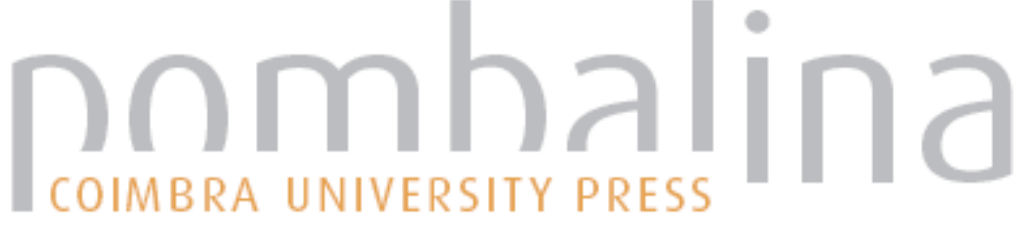

\section{As mil imagens de uma palavra}

\author{
Autor(es): Bahia, Sara
}

Publicado por: Imprensa da Universidade de Coimbra

URL

persistente: URI:http://hdl.handle.net/10316.2/39999

DOI: $\quad$ DOl:https://doi.org/10.14195/978-989-26-1115-0_7

Accessed : $\quad$ 26-Apr-2023 11:11:10

A navegação consulta e descarregamento dos títulos inseridos nas Bibliotecas Digitais UC Digitalis, UC Pombalina e UC Impactum, pressupõem a aceitação plena e sem reservas dos Termos e Condições de Uso destas Bibliotecas Digitais, disponíveis em https://digitalis.uc.pt/pt-pt/termos.

Conforme exposto nos referidos Termos e Condições de Uso, o descarregamento de títulos de acesso restrito requer uma licença válida de autorização devendo o utilizador aceder ao(s) documento(s) a partir de um endereço de IP da instituição detentora da supramencionada licença.

Ao utilizador é apenas permitido o descarregamento para uso pessoal, pelo que o emprego do(s) título(s) descarregado(s) para outro fim, designadamente comercial, carece de autorização do respetivo autor ou editor da obra.

Na medida em que todas as obras da UC Digitalis se encontram protegidas pelo Código do Direito de Autor e Direitos Conexos e demais legislação aplicável, toda a cópia, parcial ou total, deste documento, nos casos em que é legalmente admitida, deverá conter ou fazer-se acompanhar por este aviso.

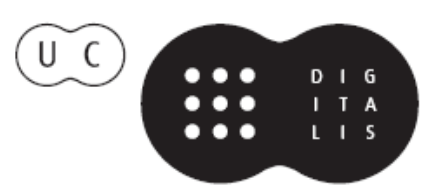




\section{JOÃO CORRÊA-CARDOSO MARIA DO CÉU FIALHO}

(Coordenadores)

\section{A LINGUAGEM NA PÓLIS}

IMPRENSA DA UNIVERSIDADE DE COIMBRA COIMBRA UNIVERSITY PRESS
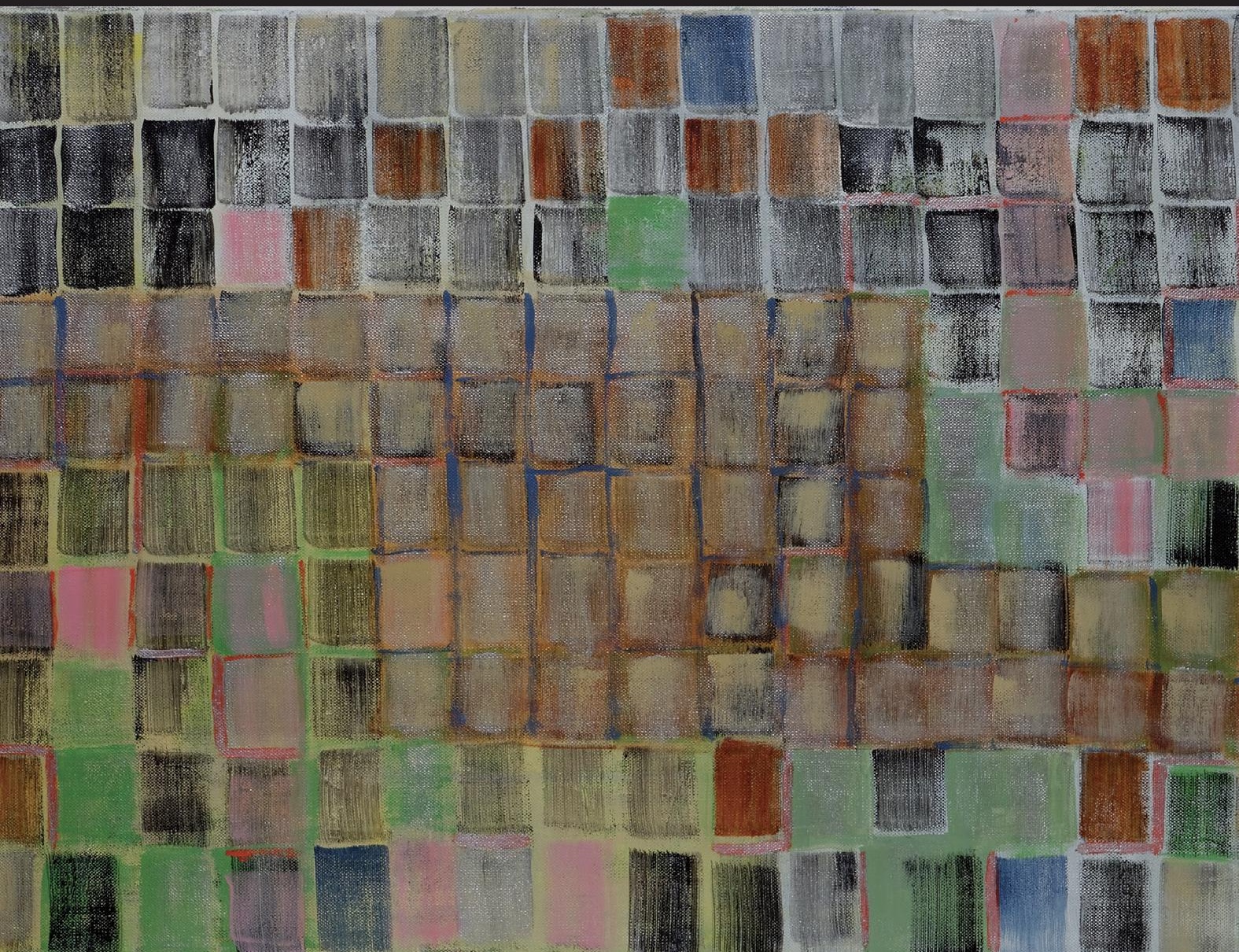


\title{
AS MIL IMAGENS DE UMA PALAVRA
}

Sara Babia

Universidade de Lisboa sarabahias@gmail.com

Resumo: Análise das relações entre as imagens e as palavras e consideração da sua importância na construção do conhecimento e das suas potencialidades criativas.

Palavras chave: imagem; palavra; psicologia; linguística; semiótica.

\begin{abstract}
Analysis of the relationships between images and words and of their role in the knowledge production and assessment of their creative potencialities.
\end{abstract}

Keywords: image; word; psychology; linguistics; semiotics.

\section{Resumo}

Em 1921, o publicitário Fred Barnard proferiu uma frase que viria a tornar-se célebre: «uma imagem vale mil palavras" (v.g. Knowles, 2004). Porém, a banalização da imagem e da arte que se seguiu acabou por conduzir à incapacidade de se reparar nas mil palavras de uma imagem ou nas mil imagens de uma palavra. Na base da deturpação do sentido da frase de Barnard parece estar um investimento académico cada vez maior na especialização e concomitantemente 
menor na criatividade, uma dificuldade crescente em visualizar e uma capacidade de abstração cada vez menos desenvolvida nos públicos mais jovens. "Ver" as mil imagens de uma palavra ou as mil palavras de uma imagem implica ser capaz de: (1) aprofundar o conhecimento, isto é, ter consciência da complexidade da sua organização e a complementaridade entre as suas diferentes expressões; (2) saber observar, ver e reparar; (3) ser crítico, ou seja, desafiar o que se sabe, inventar, colocar questões, valorizar diferentes perspetivas; e, ainda, (4) ser prático, ou seja, aplicar o conhecimento.

"As palavras são coisas, e são uma pequena gota de tinta caindo como orvalho num pensamento, produzindo aquilo que faz milhares, talvez milhões, pensarem» (Lord Byron) $)^{1}$

Em 1917, no romance-monólogo entre o orador e o filósofo, Raul Brandão explicava que "Nenhum de nós sabe o que existe e o que não existe. Vivemos de palavras. Vamos até à cova com palavras. Submetem-nos, subjugam-nos. Pesam toneladas, têm a espessura de montanhas. São as palavras que nos contêm, são as palavras que nos conduzem». O Húmus de Raúl Brandão constitui um meme deixado às gerações que se seguiram. Termo cunhado por Dawkins (1976), um meme é uma herança cultural, ideia, língua, som, desenho, capacidade, valor estético ou ética e que se traduz por palavras e/ou imagens. Infelizmente assistimos hoje a uma certa incapacidade de incorporar alguns dos memes nas memórias individuais e coletivas, pela dificuldade, relutância, ou mesmo impossibilidade, de reparar

1 Tradução livre do poema encontrado em John Bartlett [1992, Familiar quotations: A collection of passages, phrases, and proverbs raced to their sources in ancient and modern literature. (16 $6^{\text {th }}$ ed.). Boston, Little Brown]. 
nas mil imagens de uma palavra ou nas mil palavras de uma imagem. A frase de Fred Barnard "uma imagem vale mil palavras» parece já não surtir o eco que teve antes da banalização da imagem (e da arte) que se seguiu à sua divulgação. Ao longo do chamado século da imagem, a proliferação da imagem nos contextos mais diversificados ${ }^{2}$ acabou por a banalizar e conduzir a uma menor apreciação e a um menor impacto da imagem enquanto veículo rico de informação. Subjacente à desfiguração do sentido da frase de Barnard parece estar um maior investimento na especialização e menor na criatividade; uma dificuldade crescente em visualizar e uma capacidade de abstração cada vez menos desenvolvida nos públicos mais jovens.

Apesar de social e culturalmente valorizada, a especialização centrada num determinado domínio do conhecimento acarreta consequências nefastas em termos da interpretação de imagens e de palavras, e, em última instância, da produção de novos conhecimentos. A leitura de uma imagem exige flexibilidade na medida em que é preciso visualizar diferentes perspetivas e conceitos, mesmo que não pareçam ser relevantes. Por seu turno, a visualização de diferentes perspetivas e conceitos exige flexibilidade cognitiva e criatividade que implicam um conhecimento aprofundado de um determinado domínio do conhecimento (Simonton, 1988). No entanto, como referem Sternberg \& Lubart (1991) é necessário saber-se o suficiente sobre um tema, mas não demasiado. ${ }^{3} \mathrm{Na}$ realidade, se por um lado, o conhecimento aprofundado permite «ancorar» a informação (v.g. Ausubel, 1960), por outro a hiperespecialização provoca a rigidez cognitiva e é limitativa, na medida em que os especialistas sabem

\footnotetext{
2 Por exemplo, podemos referir as reproduções de obras de pintura em cartões de Natal, em caixas de chocolate ou em perfumes.

${ }^{3}$ Isaac Newton começou a trabalhar as descobertas que viriam a revolucionar o conhecimento (a lei da gravitação universal, o cálculo infinitesimal, a natureza da ótica). No ano da Peste Negra de 1666 as instituições públicas britânicas viram-se obrigadas a fechar as suas portas. Newton já tinha concluído os seus estudos em Cambridge, ou seja, já sabia o suficiente sobre tais assuntos, mas não em demasia.
} 
distinguir demasiado bem o relevante do irrelevante, e a flexibilidade e a criatividade envolvem a associação de diferentes domínios do conhecimento (v.g. Sternberg / Lubart, 1991). Neste sentido, a hiper-especialização não promove a criatividade (Martindale, 1999).

Por outro lado, a banalização da imagem parece ter levado as pessoas a fruírem cada vez menos das múltiplas expressões artísticas com suporte em palavras e/ou imagens. A par desta limitação, a capacidade de abstração fundamental para retirar sentido de palavras e/ou imagens também parece desenvolver-se cada vez mais tardiamente. Se o acesso à abstração ocorria há meio século atrás por volta dos quinze e dezasseis anos (v.g. Piaget e Inhelder, 1958), hoje este acesso parece ocorrer mais tardiamente (v.g. Bryant, 1985; Sutherland, 1992). Algumas investigações têm mesmo verificado que muitos adultos não conseguem utilizar a abstração, tendendo a utilizar uma estrutura concreta em muitas circunstâncias (v.g. Cowan, 1978). No entanto, é a capacidade de abstração que permite a assunção de múltiplas perspetivas e enquadramentos bem como a construção de novos significados (v.g. Piaget, 1977).

\section{Das imagens das palavras}

A análise de palavras e de imagens parece ser cada vez menos trabalhada e cada vez mais inacessível devido à banalização da imagem, pelas barreiras à criatividade e pela falta de oportunidades de abstração. A sua análise exige a utilização de estratégias (e de capacidade e competências) mnésicas, linguísticas, de visualização e de abstração bem desenvolvidas porque imagens e palavras estão interligadas.

Segundo Paivio (1971), o registo da informação na memória é realizado através de um código dual constituído por palavras e/ou imagens. No entanto, para Kosslyn (1990), dois terços das imagens 
com que lidamos mentalmente no nosso dia a dia são visuais. Gruber (1981) refere que formamos imagens de largo espetro abrangentes que funcionam como um esquema capaz de assimilar uma variedade lata de perceções, ações e ideias. Cornelius e Casler (1991) designam este processo de imaginação, especificando que esta possui o poder de formar imagens mentais que não estão realmente acessíveis aos sentidos e que permitem criar novas ideias com base na combinação de ideias anteriormente não relacionadas. Salientando a relevância da imagem na estruturação do conhecimento, Damásio (1999) refere que todo o ser humano vive de imagens e que a produção de imagens do interior para o exterior, conscientes ou não conscientes, nunca para.

A imagem está associada à produção do conhecimento. Shepard (1978) explica que muitas das inovações científicas tiveram como base imagens, porque a sua visualização oferece alternativa à linguagem e aos modos tradicionais de pensamento porque as imagens produzem uma maior vivacidade emocional. Para além disso, a sua riqueza e relação com fontes externas pode sugerir mais interações do que a linguagem e a sua natureza torna-as suscetíveis de serem manipuladas intuitivamente. Shepard (1978) refere, ainda, que a suscetibilidade do sistema visual para a simetria facilita a descoberta de simetrias e de constantes estruturais nos diversos domínios do conhecimento. Segundo Tardiff \& Sternberg (1988), a capacidade para formar imagens é uma característica das pessoas criativas que envolve a produção de visualizações internas, a construção de novas estruturas, a utilização de categorias abrangentes e a produção de imagens que podem produzir alterações no conhecimento e avanços ou recuos na compreensão do mundo.

Para Havener \& Thorpe (1996), a imagem auxilia a utilização de capacidades sintéticas para integrar a informação num quadro, relaciona conhecimentos, resultando daí uma compreensão única e profunda dos fenómenos que motivam a inovação. Assim a imagem funciona como uma alavanca que desperta as relações inerentes à 
rede de conhecimentos e facilita o processo criativo, porque conduz à criação de novos modelos e metáforas (Paivio, 1971). Em suma, o encontro de padrões de conhecimento constitui o tema central da descoberta, da invenção e da exploração de qualquer domínio do conhecimento, quer seja suportado por palavras quer por imagens.

\section{Das palavras das imagens}

As imagens constituem importantes auxiliares para a tomada de decisões diretas, para a organização sequencial e analítica da informação, para a resolução de problemas concretos e, também, para o raciocínio abstrato. Consequentemente, Palavras e Imagens ou Imagens e Palavras são fundamentais para a representação, interpretação e comunicação do conhecimento e do mundo que, por sua vez, dependem da perceção e da imagética. A perceção consiste na interpretação que damos à informação sensorial. Os diferentes sistemas neuronais processam impulsos específicos em simultâneo com base no conhecimento acumulado, nas experiências anteriores e na estrutura de desenvolvimento alcançada. Neste sentido, o que se conhece influencia aquilo que se perceciona. Por seu turno, a imagética consiste na representação de algo que não está fisicamente presente e difere substancialmente consoante as pessoas. Enquanto algumas pessoas possuem uma capacidade imagética elevada e são capazes de representar na mente inúmeros pormenores icónicos, outras apenas conseguem relatar uma descrição vaga de um objeto, sem riqueza e detalhe.

$\mathrm{Na}$ investigação sobre este domínio persiste a controvérsia relativamente ao processo de representação imagética. Para a teoria estrutural, a informação é armazenada através de um código analógico. Os mesmos mecanismos do sistema visual são ativados quando se perceciona ou imagina objectos ou acontecimentos. 
Aludindo ao modelo da simulação do computador, Kosslyn (1990) refere que as imagens apresentam duas componentes: a representação superficial, quasi-pictórica, e a representação profunda, armazenada na memória a longo prazo e utilizada para gerar a representação superficial. As representações profundas podem ser literais, isto é, codificações ou proposicionais, isto é, descrições verbais de um objeto ou de uma cena. Outra perspetiva defende a teoria do código proposicional que explicita que toda a representação é abstrata e se assemelha à linguagem. O armazenamento não é nem visual, nem espacial e não se assemelha ao estímulo inicial (Matlin, 1994). A informação é armazenada em termos de proposições ou conceitos abstratos que descrevem relações, sendo as imagens mentais posteriormente construídas. Para Pylyshyn (1984), seria impraticável, em termos de espaço, armazenar a informação em termos de imagens mentais.

Perceção, imagética e abstração são aspetos relevantes para as operações mentais de raciocínio em situações novas (Primi, 2002). A sua utilização permite fazer inferências, ou seja, ler nas entrelinhas, completar a informação que não se perceciona ou que não se vê, ouve, lê, a partir de padrões (conhecidos ou inovadores) com base na informação fornecida pelos sentidos. Perceção, imagética e abstração constituem também os pilares fundamentais do processo de codificação selectiva da informação, passo determinante para a resolução inteligente (e criativa) de problemas (Sternberg, 1977) e da inferência. A inferência parte sempre de uma informação parcialmente apresentada, como é o caso de uma imagem ou de uma palavra. A dedução ou indução de padrões a partir dessa informação parcial permite antecipar e atribuir significado ao que vemos, ouvimos, lemos ou sentimos. Esta necessidade de uma inferência constante de padrões pode ser motivada pela necessidade de sobrevivência a partir da procura das leis da natureza, como 
no caso do conhecimento científico ou pela produção na mente da observação do mundo, como no caso do conhecimento artístico.

\section{Da abstração de palavras e de imagens}

Ler nas entrelinhas implica ser capaz de abstrair. A abstração é a representação mental de objetos ou acontecimentos que não possuem uma realidade concreta (Mercer, 2002) e depende da aquisição da estrutura operatória formal (Piaget / Inhelder, 1958) que possibilita o acesso ao improvável, ao impossível, à relativização de probabilidades e de possibilidades, à formulação de hipóteses, à planificação e à sistematização de conceitos e de conhecimentos. Algumas investigações têm verificado que muitos adultos não chegam a aceder plenamente à estrutura operatória formal e tendem a utilizar uma estrutura concreta em muitas circunstâncias (v.g. Cowan, 1978), cingindo-se ao imediato, observável e diretamente manipulável e assumindo que existe só uma solução possível e não uma multiplicidade de soluções, interpretação e formas de resolução. O raciocínio concreto conduz, ainda, à falta de consciência do erro, à dificuldade em aplicar consistentemente regras e em assumir a incerteza de uma solução (Lieberman, 1970). Apesar das limitações, as pessoas "concretas" conseguem conhecer muitos factos (Mercer, 2002), mas não conseguem retirar as mil informações contidas nas palavras e nas imagens.

Como passar, então, do concreto para o abstrato? Como facilitar a leitura das entrelinhas? Como inferir as mil imagens ou palavras de uma palavra ou de uma imagem? A resposta a estas questões implica necessariamente uma mudança educacional profunda para que a atribuição do significado aos memes possibilite a produção de conhecimentos inovadores promotores da adaptação às rápidas e imprevisíveis transformações a que temos assistido nas últimas décadas. 


\section{Das palavras e das imagens ao ser}

Aprofundar e desafiar o conhecimento, reparar em múltiplas perspetivas e saber aplicar na prática quotidiana e académica o que se conhece constituem as principais implicações educacionais da valorização da imagem, quer esteja contida em palavras, quer noutras imagens dos memes que transmitimos aos mais jovens. Para Csikszentmihalyi (1988) qualquer novo pedaço de informação que se junta a um domínio do conhecimento constituirá a fonte de informação para a nova geração de "criadores".

Aprofundar o conhecimento, significa, basicamente, saber mais e melhor através do treino de competências de linguagem, de visualização, de abstração. Implica, por parte do sujeito da aprendizagem e também do formador, organizar a informação, facilitar a sua disponibilização, relacionar conceitos e factos, estimular a interrogação, promover a formulação de hipóteses, associar o que se vê, ouve e lê às "âncoras" do conhecimento e, paralelamente, reforçar, reconstruir ou reformular o que já se sabe através de leituras, do treino de competências de linguagem, de visualização, de abstração, de automatização, de ensaio e de prática. Saber mais e melhor é sinónimo de aprofundar as especificidades de uma matéria e de dar a conhecer novas possibilidades através de atividades como a resolução de exercícios, de problemas, charadas ou a análise de imagens.

No entanto, importa conseguir ir para além do óbvio para se conseguir ver nas entrelinhas e para além das linhas e utilizar e reutilizar a linguagem, ou seja, importa ser crítico. Desafiar o que se sabe, mais do resolver problemas ou responder a questões, é inventar, encontrar problemas e colocar questões. O levantamento de questões, a descoberta de problemas e o encontro de soluções (v. g. Getzels / Csikszentmihalyi, 1975) constituem metas desenvolvimentistas determinantes para a experimentação ativa e a manipulação 
direta de ideias, conceitos e objetos. A construção do conhecimento não é um processo passivo, mas sim ativo porque cada pessoa cria as experiências que influenciam e enriquecem o seu desenvolvimento (v.g. Bell / Harper, 1977). Na medida em que a reprodução do conhecimento não basta, é necessário desafiar a produção de novos conhecimentos. Por isso, importa incentivar uma atitude crítica, fomentar a questionação, colocar a tónica na criação de problemas e, também não de somenos importância, gerar ideias e soluções, comunicá-las e convencer os outros da sua relevância.

O aprofundamento e o desafio do conhecimento são indissociáveis da capacidade de observar, ver e reparar. Saber ver é, como se defendeu, determinante para a representação do conhecimento. Nesse sentido, importa analisar as múltiplas mensagens contidas numa palavra ou numa imagem; valorizar diferentes expressões e formas de interpretação; encorajar a flexibilidade e reforçar abordagens únicas, invulgares e diferentes. Saber ver implica também questionar pressupostos e "verdades" e mostrar o que está para além do literal e do óbvio. Incentiva-se o olhar estimulando a questionação e uma atitude crítica ao saber incontestável, fomentando a curiosidade, a elaboração de perguntas e a associação entre conceitos e ajudando a assumir a complexidade do conhecimento. Na medida em que visualização e abstração se entrecruzam, o jogo dinâmico entre o concreto e o abstrato traz mais-valia na compreensão, interpretação, recordação e aplicação das mil imagens de uma palavra quando se recorrer à palavra, ao objeto concreto, à imagem mental abstrata e, logicamente, recorrer a ambos em simultâneo.

Por fim, a produção do conhecimento só é possível se se reflectir sobre o modo como o meio influencia e é influenciado por determinado conhecimento, o que implica fomentar a autonomia. A autonomia é conseguida quando se interioriza a ideia de que ninguém pode aprender por outra pessoa e que a responsabilidade e capacidade de aprender residem no próprio. Mas um conhecimento 
é interiorizado quando se compreende como se pode ser aplicado na prática que se aprofundou e como se pode interligá-lo a outros conhecimentos. Assim, as múltiplas leituras de uma palavra ou de uma imagem podem ser integradas no "saber ser" quando se sente necessidade da sua aplicação prática e se tem oportunidade de manipular diretamente, relacionando a palavra (e a imagem) com a vivência quotidiana, verificando a aplicação, vantagens e desvantagens de cada perspetiva e apelar para a descoberta da origem das palavras e das imagens.

As palavras, com as suas múltiplas imagens, e as imagens, com as suas múltiplas palavras, são memes que vale a pena passar às gerações seguintes, para que eles os reproduzam ou produzam novos conhecimentos a partir deles. Por tudo o que desenvolve, vale a pena apostar na procura das mil imagens de uma palavra ou nas mil palavras de uma imagem. Afinal, as palavras (e, acrescente-se, as imagens) são pequenas gotas de tinta que possibilita que milhares, talvez milhões, pensem, como diria Byron.

\section{Bibliografia}

Ausubel, David Paul (1960), The use of advance organizers in the learning and retention of meaningful verbal material. Journal of Educational Psychology.

Bartlett, John (1992), Familiar quotations: A collection of passages, phrases, and proverbs raced to their sources in ancient and modern literature. (16 $\left.{ }^{\text {th }} \mathrm{ed}.\right)$. Boston, Little Brown.

Bell, Richard Q. / Harper, Lawrence V. (1977), Child effects on adults. Hillsdale, NJ: Lawrence Erlbaum.

Brandão, Raul (1917, 2000), Húmus. (2. ${ }^{\text {a }}$ ed., crítica de Maria João Reynaud). Porto, Campo das Letras.

Bryant, Peter (1985), The distinction between knowing when to do a sum and knowing how to do it. Educational Psychologist, Vol.5, Issue 3 \& 4.

Cornelius, Georgianna / Casler, Jacqueline (1991), Enhancing creativity in young children: Strategies for teaching. Curriculum and Teaching, 6 (2).

Cowan, Philip (1978), Piaget with Feeling. New York, Holt, Rinehart and Winston. 
Csikszentmihalyi, Mihaly (1988), Society, culture, and person: a systems view of creativity. In: The nature of creativity: contemporary psychological perspectives. Robert J. Sternberg (Ed.), New York: Cambridge University Press.

Damásio, António (1999), O sentimento de si. Mem Martins, Publicações EuropaAmérica.

Dawkins, Richard (1976), The selfish gene. New York, Oxford University Press.

Getzels, Jacob W. / Csikszentmihalyi, Mihaly (1975), From problem solving to problem finding. In: Perspectives in creativity, Irving. A. Taylor \& Jacob. W. Getzels (Orgs.). Chicago, Aldine Publishing.

Gruber, Howard E. (1981), Darwin on man. Chicago, University of Chicago Press.

Havener, Cliff / Thorpe, Margaret (1996), The basis of genius or the essential flaw in our education system and how to fix it. Retirado em Junho de 2002 de http:// www.forseekers.com

Kosslyn, Stephen M. (1990), Mental imagery. In: Visual cognition and action: An invitation to cognitive science. Daniel N. Osherson, Stephen Michael Kosslyn \& John M. Hollerbach (eds.), Vol. 2, Cambridge, Massachusetts, MIT Press.

Lieberman, Lewis R. (1970), Concept Breadth and the Childish Ignorance Hypothesis, Journal of Abnormal Psychology 76 (1).

Martindale, Colin (1999), Biological Bases of Creativity. In: Handbook of Creativity Robert J. Sternberg (ed.), New York, Cambridge University Press.

Matlin, Margaret (1994), Cognition. ( $3^{\text {rd }}$ ed.) Fort Worth, Hartcourt Brace Publishers.

Mercer, Jean (2002), The Cognitive Development and Academic Achievement. In: The Review for the Study of College Teaching. Vol.1, William C. Lubenow (ed.). New Jersey, The Institute for the Study of College Teaching.

Oxford Dictionary of Quotations (The), (6 $6^{\text {th }}$ ed., 2004) Edited by Elizabeth Knowles, USA, Oxford University Press.

Paivio, Allan (1971), Imagery and verbal processes, New York, Holt, Rinehart and Winston.

Piaget, Jean (1977), O desenvolvimento do pensamento: equilibração das estruturas cognitivas, Lisboa, D. Quixote.

Piaget, Jean / Inhelder, Bärbel (1958), The Growth of Logical Thinking from Childhood to Adolescence, New York, Basic Books.

Primi, Ricardo (2002), Complexity of geometric inductive reasoning tasks: Contribution to the understanding of fluid intelligence, Intelligence, 30.

Pylyshyn, Zenon W. (1984), Computation and cognition: Toward a foundation for cognitive science, Cambridge, Massachusetts, MIT Press.

Shepard, Roger Newland (1978), Externalizations of mental images and the act of creation. In: Visual learning, thinking and communication. Bikkar S. Randhawa \& William E. Coffman (Eds.), New York, Academic Press.

Simonton, Dean Keith (1988), Creativity, leadership, and chance. In: The nature of creativity: contemporary psychological perspectives. Robert. J. Sternberg (Ed.), NY, Cambridge University Press. 
Sternberg, Robert J. (1977), Intelligence, Information Processing, and Analogical Reasoning, Hillsdale, NJ, Erlbaum.

Sternberg, Robert J. / Lubart, Todd I. (1991), An investment theory of creativity and its development, Human Development, 34.

Sutherland, Peter (1992), Cognitive development today: Piaget and his critics, London, Paul Chapman Publishing, Ltd.

Tardiff, Twila Z. / Sternberg, Robert J. (1988), What do we know about creativity? In: The nature of creativity. Robert Sternberg (ed.). Cambrigde, Cambridge University Press. 